\title{
CAPACITY BUILDING THROUGH PROJECT BASED LEARNING IN BAYESIAN STATISTICS
}

\author{
Shirlee R. Ocampo ${ }^{1}$ and Bladimir C. Ocampo ${ }^{2}$ \\ ${ }^{1}$ De La Salle University, Manila, Philippines \\ ${ }^{2}$ Centro Escolar Las Pinas, Westfield Science Oriented School, Philippines \\ shirlee.ocampo@dlsu.edu.ph
}

\begin{abstract}
Outcome-based education requires statistics education in the $21^{\text {st }}$ century to be structured holistically by allowing the students to work with real life data along with visualization, computation, and learning outputs. The new $K-12$ curriculum resulted to a chain reaction in the Statistics undergraduate program by including alternative statistical frameworks such as Bayesian statistics. This paper focuses on project-based learning approach on designing learning outputs for undergraduate and graduate students in Bayesian statistics. The stages of project-based learning in completing these Bayesian learning outputs have helped in building the capacities of the students to understand the essential concepts in Bayesian inference and do computations using software. Some of the learning outputs are cited. Insights are helpful in making the syllabus of Bayesian Statistics and Inference of undergraduate Statistics program. Project based learning incapacitates the students to do Statistics research in an organized manner and make decisions based on data.
\end{abstract}

\section{OUTCOMES-BASED EDUCATION}

Due to many educational reforms, many higher education institutions in the Philippines have started implementing Outcomes-Based Education (OBE) system on school level. According to Spady (1994), OBE means "clearly focusing and organizing everything in an educational system around "what is essential for all students to be able to do successfully at the end of their learning experience." Furthermore, he said that "an OBE means focusing and organizing an institute's entire programs and instructional efforts around the clearly defined outcomes we want all students to demonstrate when they leave institute". This means that OBE is an educational system that organizes the whole program into curriculum, instruction and assessment that focuses on what students can actually do after they are taught. The important components of OBE educational are developing a clear set of learning outcomes, and establishing the conditions and opportunities within the system that enable and encourage all students to achieve those essential outcomes (Duradundi \& Dipak, 2017).

"OBE is a process that focuses on what is to be learned - the outcomes" (Kudlas, 1994). Many dictionaries define "outcome" as "something that follows as a result or a consequence", or "a result or an end-product." According to Spady and Marshall (1991), "Outcomes are clear, observable demonstrations of student learning that occur after a significant set of learning experiences. They are not values, attitudes, feelings, beliefs, activities, assignments, goals, scores, grades, or averages, as many people believe. Typically, these demonstrations, or performances, reflect three things:

(1) What the student knows;

(2) What the student can actually do with what he or she knows;

(3) The student's confidence and motivation in carrying out the demonstration.

A well-defined outcome will have clearly defined content or concepts and be demonstrated through a well-defined process beginning with a directive or request such as 'explain', 'organize', or 'produce"'.

Furthermore, Spady (1994) stated that the most important outcomes are those that reflect real life roles that learners will perform the moment they exit the education system called culminating outcomes." It is then important to link the program level outcomes with the culminating outcomes so as to ensure that education prepares the students to do their future roles. Thus, OBE focused more on the results of education.

In the Philippines, the implementation of OBE has been emphasized by the Commission on Higher Education (CHED) by issuing a memorandum order (CMO No. 46, s. 2012) entitled, "PolicyStandard to Enhance Quality Assurance in Philippine Higher Education through an Outcomes-Based and Typology Based QA". It was then followed in 2014 with the release of the Handbook of Typology, Outcomes-Based Education, and Sustainability Assessment. 


\section{PROGRAM OUTCOMES IN B.S. STATISTICS}

With the emphasis of OBE in higher education and with the K-12 educational curriculum reforms which consequently resulted to chain reactions in baccalaureate programs including the Statistics degree program. The Statistics baccalaureate program now includes alternative statistical frameworks such as the Bayesian statistics. In making the syllabi of the courses including Bayesian Statistics and Inference under the OBE educational system, one of the things that should be identified and explicitly stated are the culminating outcomes, what we want the students to be able to do successfully when they graduate from the Statistics program. Some of the culminating outcomes are enumerated in Table 1 .

Table 1. Program Outcomes

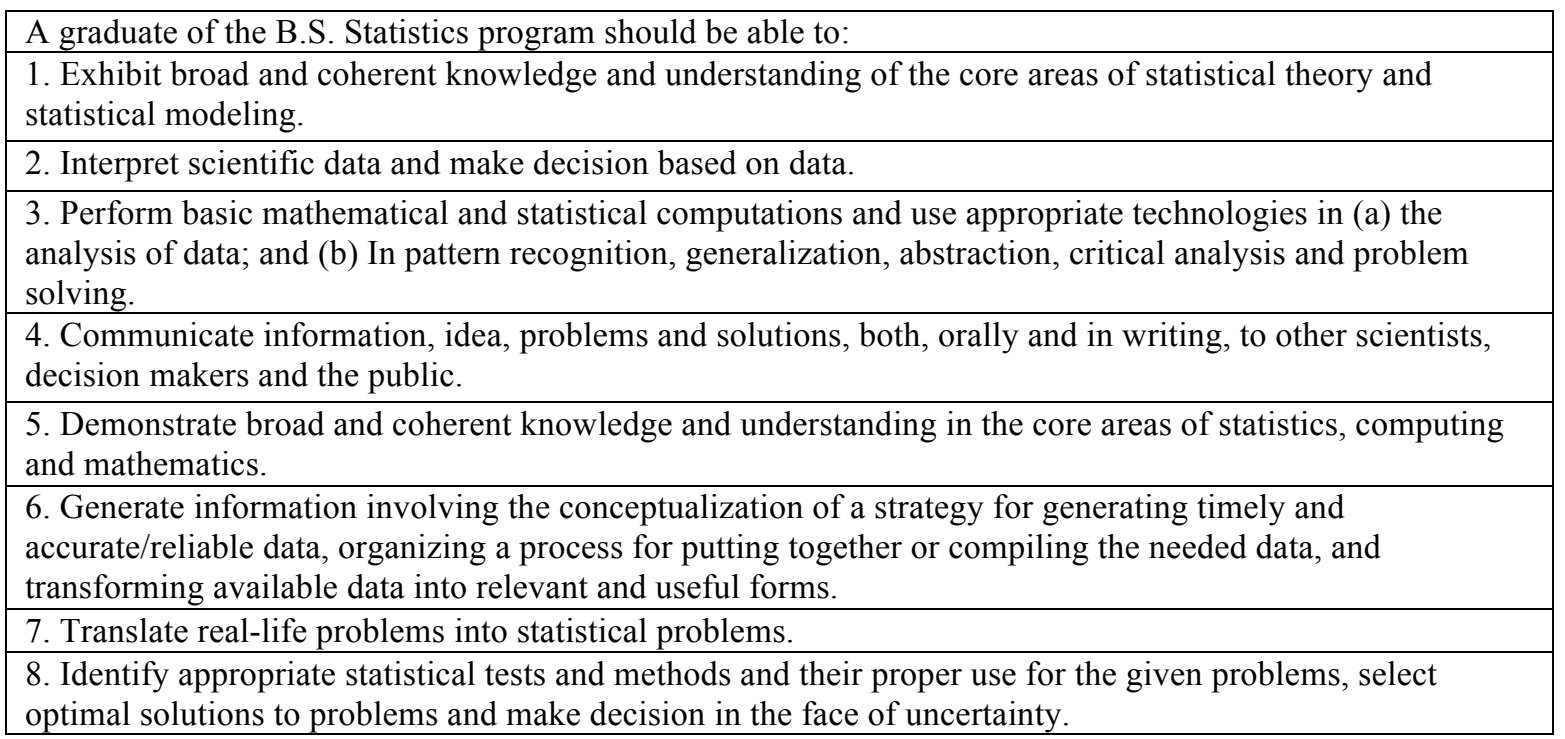

The table of program outcomes is followed by the description of the course culminating product. For the Bayesian Statistics course, the learning outcome and final output is shown in Table 2. This is followed by a rubric for assessment.

Table 2. Bayesian Statistics Course Learning Outcome and Output

As evidence of attaining the above learning outcomes, the student is required to submit the following during the indicated dates of the term.

\begin{tabular}{|l|l|l|}
\hline Learning Outcome & Required Output & Due Date \\
\hline At the end of the course, the student will & Inquiry-based individual and group & End of the Course \\
apply appropriate Bayesian statistical & presentations highlighting the uses of \\
concepts, processes, tools, and & Bayesian statistics in different problem \\
technologies in the solution to various & situations encountered in business, health, \\
conceptual and real-world problems. & $\begin{array}{l} \\
\text { environment, and other related fields with } \\
\text { the use of statistical software. }\end{array}$ & \\
\hline
\end{tabular}

\section{PROJECT-BASED LEARNING}

OBE involves "everything in an educational system around what is essential for all students to be able to do successfully at the end of their learning experience." (Spady, 1994). One of the principles that can be used to make good outputs showcasing learning outcomes is the project-based learning (PBL). PBL is an instructional model that involves students in investigations of compelling problems that culminates in authentic products (Intel Teach Program, 2012). It refers to designing, planning and carrying out an extended project that produces a publicly-exhibited output such as a product, publication, or presentation. Such approach encourages active inquiry, higher order thinking skills, collaboration, and effective communication. Under PBL, there is a situation problem with no 
predetermined answer where students design the process to reach solutions and final products collaborating ad evaluating. A project planner is encouraged with learning outcomes, output/product summary, timeline, presentation/exhibition plan, and assessment criteria.

\section{PBL IN BAYESIAN STATISTICS}

The $\mathrm{K}$ to 12 educational reforms consequently led to revamps to the baccalaureate Statistics courses. Bayesian Statistics, a graduate elective course in M.S. Statistics, is now included in the undergraduate statistics courses. The course is designed to deal with elements of Bayesian inference, specifying priors, assessment of prior, likelihood, and posterior distributions, Bayesian estimation and hypothesis testing, predictive distribution and asymptotics, Bayesian hierarchical models, introduction to Empirical Bayes, and Bayesian regression with the use of statistical software. Students may use any statistical software they are familiar with such as R, SAS, WinBUGS, OpenBUGS, Python, and many more. At the end of the course, groups of students are required to present learning outputs on any applications of Bayesian Statistics using real-life data. Suggested topics for culminating learning outputs include hierarchical Bayesian modelling, Markov Chain Monte Carlo (MCMC), Gibbs Sampling, Grid Approximation, Bayesian mapping, Bayesian networks, and the like. The syllabus of this course was design with the help of insights gained from undergraduate and graduate courses with integrated Bayesian statistics concepts with learning outputs. Stages of project based approach were utilized by these groups of students to complete final outputs in Bayesian statistics which incapacitates them to do research papers for presentation in class or research congress, and possibly for publication. PBL promotes independent and inquiry learning among students and enhances their research skills integrated with technological/computational skills. PBL approach also helped the students to understand in depth essential concepts in Bayesian statistics and inference. Some of the final outputs along with their descriptions are enumerated below.

1. Predicting Gender Representation in Male-Dominated Fields Across Using Grid Approximation

The norms of society have stipulated that finding out the majority of volume of genders in the workplace can be easily depicted with regards to the type of affiliation. This 2018 , women represented only $38 \%$ of non-technical positions in the tech industry, despite holding $57 \%$ of all bachelor's degrees in 2015. Statistics from the Bureau of Labor Statistics is in par with this showing that the percentage of female computer programmers around the USA is only at $28.6 \%$. This norm is also carried out in college which could be a factor for why these statistics are present in the workplace. For instance, the stereotype for Computer Science is that most of the students studying this degree program are probably males, while Liberal Arts or Business students would say otherwise. With the change of society throughout the years especially with Millennials and Generation $Z$ students now taking up college, are the norms still the same? This study focuses on computing the probability of a male being in a particular course and whether it still remains constant throughout the batches of college students with the use of Bayesian inference and grid approximation. The study aims to determine whether the norms have indeed changed from past college batches to more recent batches which are said to be the next generation.

2. A Bayesian Approach to the Interval Estimation of the National Accounts of the Philippines (Poquiz \& Ocampo, 2017) (Presented at the DLSU Research Congress 2017, De La Salle University, Manila, Philippines, June 20-22, 2017)

This paper aims to suggest an alternative method for the interval estimation of the Quarterly National Accounts of the Philippines. The Gross Domestic Product (GDP) is perhaps the most closely monitored measure of economic performance. While point estimates of GDP growth is important, one could argue that interval estimates of the said economic indicator deserve more attention. GDP estimates, like most official statistics, is subject to revisions-a result of measurement errors and the incompleteness of data during the initial estimation. Revisions highlight the uncertainty about the accuracy of the initial estimates. If the preliminary estimate would be revised in the future, how likely is it that the decisions made based from the preliminary estimates would not be far off from decisions supposedly made had the final 
estimates been available? Interval estimation resolves this by reflecting a degree of uncertainty around the preliminary point estimate and indicate a range where the true value of the GDP growth could be located. At present, the Philippine Statistics Authority (PSA) publishes interval estimates of real GDP growth rates alongside the point estimate of the GDP growth. The confidence interval is computed using the methodology proposed by the paper of Virola and Parcon (1996). The study assumed that the final estimate of the GDP growth is its true value and they generated intervals based on the tendency for revision. A study by Poquiz, Moscoso, and Guiam (2016) found that the interval estimates published by the PSA failed to capture the final estimate of GDP growth majority of the time. They conclude that the interval estimates produced by the PSA failed to serve its purpose. This paper explores the use of Bayesian Inference in generating interval estimates for GDP growth. The final estimate of GDP growth was expressed as a linear function of the preliminary GDP growth estimate. Credible intervals were then generated for the regression parameters and predictions from the resulting models served as the upper and lower limits of GDP growth. The methodology was tested assuming a Uniform Prior, a Gaussian Prior, and the Jeffrey's Non-Informative prior. The resulting interval estimates were also compared to the intervals generated using the frequentist approach. The results show the intervals generated by the Bayesian approach was considerably better in terms of capturing the final value of GDP growth compared to the intervals generated from the methodology of the PSA.

Other research outputs of students are enumerated below are "Sleep Pattern Analysis Using MCMC", "Bayesian Mapping of Reefs with Poor Coral Cover", "Bayesian Analysis of Mental Health Care Among Southeast Asian Countries", and many more. Such research outputs indicate that allowing the students work on these outputs using PBL capacitates them to do research and other products under the OBE system.

\section{CONCLUSIONS}

In the Philippines, CHED has emphasized the implementation of the OBE educational system involves culminating programs and learning outputs. Educational reforms such as $\mathrm{K}$ to 12 curriculum have affected the baccalaureate degree programs including the B.S. Statistics program which now includes Bayesian Statistics as one of the required major courses. Program outcomes, learning outcomes and final output have been integrated in course syllabi. PBL steps have helped the students to complete their Bayesian final projects can build their capacities to understand in depth Bayesian statistics concepts and to enhance their research skills in an organized manner to make good decisions based on data. Insights from completed projects using PBL approach are helpful in making the syllabus of Bayesian Statistics course.

\section{REFERENCES}

Duradundi, S. B., \& Dipak, N. M. (2017). An Outcome-Based Education (OBE): An Overview. International Journal of Advanced Research in Education and Technology, 4(1), 97-100.

Intel Teach Program (2012). Benefits of Project-Based Learning. Designing Effective Projects. Intel Corporation, 1-4. Retrieved (May 29, 2019) from https://www.intel.com/content/dam/www/progr am/education/us/en/documents/project-design/projectdesign/benefits-of-projectbased-learning.pdf.

Kudlas, J. M. (1994). Implications of OBE: What you should know about outcome-based education. The Science Teacher, 61(5), 32-35.

Poquiz, J. L., Moscoso, S. R., \& Guiam, E. G. (2016). Improving the interval estimation of the quarterly national accounts of the Philippines. National Convention on Statistics.

Poquiz, J. L., \& Ocampo, S. (2017). A Bayesian Approach to the Interval Estimation of the National Accounts of the Philippines. Proceeding of DLSU Research Congress 2017. Retrieved (May 30, 2019) from https://www.dlsu.edu.ph/wp-content/uploads/pdf/conferences/research-congressproceedings/2017/CENSER/CENSER-III-042.pdf

Spady, W., \& Marshall, K. (1991). Beyond Traditional Outcomes-Based Education, Educational Leadership, 49(2), 67-72.

Spady, W. (1994). Outcome-based education: Critical issues and answers. Arlington, VA: American Association of School Administrators. 
Virola, R., \& Parcon, G. (1996). Estimating the Confidence Interval of GDP Growth Rates. National Convention on Statistics. 